\title{
FAKTOR - FAKTOR YANG MEMPENGARUHI KUNJUNGAN WISATAWAN KE KAWASAN EKOWISATA DI DESABAHOI KECAMATAN LIKUPANG BARAT KABUPATEN MINAHASA UTARA
}

\author{
Jecqerel Rio Lakuhati \\ Paulus A. Pangemanan \\ Caroline B. D. Pakasi
}

\begin{abstract}
This study aims to determine the factors - factors that affect tourist visits to the ecotourism area in the village of Bahoi. This research was conducted in May - July 2016, in Bahoi Village, West Likupang Sub-district, North Minahasa Regency. The location of this study was chosen with several considerations, namely: Bahoi Village is one of the areas that have ecotourism area that is enough to attract the interest of the surrounding community and even the foreign community. Where this ecotourism area is one of the livelihood for the people of Bahoi Village. The method used in this study is the accidental sampling method by accidental interviewing technique, ie anyone who by chance there is a research location used as a sample or research respondents. The results obtained that factors affecting tourist visits are distance traveled, age level, travel expenses, and entrance fees. Where the tendency of tourists to ecotourism diving is strongly influenced by the age level because the statistical test states that the age level is very significant. While the tendency to visit ecotourism mangrove factor that most influence is the age level, because statistical test states that age is very significant.
\end{abstract}

Keyword: Ecotourism, Tourists, Logistic Regression, Likupang Barat District

\begin{abstract}
ABSTRAK
Penelitian ini bertujuan untuk mengetahui faktor - faktor yang mempengaruhi kunjungan wisatawan ke kawasan ekowisata di Desa Bahoi. Penelitian ini dilaksanakan pada bulan Mei Juli 2016, di Desa Bahoi, Kecamatan Likupang Barat, Kabupaten Minahasa Utara. Lokasi penelitian ini dipilih dengan beberapa pertimbangan yaitu: Desa Bahoi merupakan salah satu daerah yang memiliki kawasan ekowisata yang cukup menarik minat para masyarakat sekitar dan bahkan masyarakat luar negeri. Dimana kawasan ekowisata ini merupakan salah satu mata pencaharian bagi masyarakat Desa Bahoi. Metode yang digunakan dalam penelitian ini adalah metode accidental sampling dengan teknik wawancara berdasarkan kebetulan, yaitu siapa saja yang secara kebetulan ada dilokasi penelitian dijadikan sampel atau responden penelitian. Hasil yang diperoleh bahwa faktor - faktor yang mempengaruhi kunjungan wisatawan adalah jarak yang ditempuh, tingkat usia, biaya perjalanan, dan biaya masuk. Dimana kecenderungan wisatawan untuk ekowisata diving sangat dipengaruhi oleh tingkat usia karena uji statistic menyatakan bahwa tingkat usia sangat signifikan. Sedangkan kecenderungan untuk berkunjung ke ekowisata mangrove faktor yang paling mempengaruhi adalah tingkat usia, karena uji statistik menyatakan bahwa tingat usia sangat signifikan.
\end{abstract}

Kata kunci: Ekowisata, Wisatawan, Regresi Logistic, Kecamatan Likupang Barat. 


\section{PENDAHULUAN}

\section{Latar Belakang}

Kunjungan wisatawan ke Sulawesi Utara pada tahun 2009 yang mencapai 16.700 orang merupakan kunjungan wisatawan paling tinggi selama tujuh tahun terakhir. Pada 2007 yang mencapai 12.197 orang dan pada tiga tahun berturut - turut dari 2011 sampai dengan 2013 yakni 11.876 orang, 11.694 orang, dan 11.873 orang mengalami stagnasi. Kunjungan wisatawan ke Kabupaten Minahasa Utara mencapai 11.873 orang wisatawan lokal dan 9.026 wisatawan asing pada tahun 2013. Sebagian besar wisatawan ini mengunjungi destinasi pantai. Kabupaten Minahasa Utara memiliki daya tarik wisata, dengan rincian wisata budaya, wisata religi, dan juga wisata pantai. Pemerintah Sulawesi Utara melalui Perda Nomor 1 tahun 2014 tentang Rencana Tata Ruang Wilayah Kabupaten Sulawesi Utara tahun 2013 - 2033 mencanangkan kawasan wisata di Sulawesi Utara termasuk yang terdapat di Kabupaten Minahasa Utara.

Sulawesi Utara memiliki banyak tempat wisata yang menjadi tempat kunjungan wisatawan sehingga pemerintah benar - benar berkonsentrasi pada pengembangan wisata. Ada berbagai jenis ekowisata, wisata hutan lindung, wisata cagar alam, wisata mangrove dan lain sebagainya. Salah satunya di Kabupaten Minahasa Utara, diantaranya Taman Laut Nasional Bunaken, Ekowisata Desa Bahoi, Pulau Bangka, Pulau Gangga, Kawasan Wisata Pantai Surabaya, Pantai Lihaga, dan masih banyak lagi ekowisata yang ada di minahasa utara yang masih belum diketahui. Dari beberapa kawasan ekowisata diatas, dapat diambil contoh Pantai Lihaga. Pantai Lihaga sudah banyak dikenal oleh wisatawan di Sulawesi Utara bahkan di Indonesia, pantai Lihaga memiliki beberapa tawaran ekowisata yang menarik yang bisa dirasakan dan dinikmati oleh wisatawan yang datang berkunjung dipantai Lihaga. Sama halnya dengan Desa Bahoi, yang menjadi lokasi penelitian ini, Desa Bahoi juga memiliki berbagai potensi ekowisata yang bisa dikembangkan sehingga menarik wisatawan untuk datang dan berkunjung di Desa Bahoi.
Kawasan ekowisata Desa Bahoi ini diresmikan pada tahun 2010 dengan dua keunggulan kawasan ekowisata, seperti adanya ekosistem mangrove dengan luas $\pm 10 \mathrm{Ha}$ dan diving center. Meski tergolong baru, namun kegiatan ekowisata berbasis masyarakat ini telah memberikan nilai positif bagi warga setempat. Desa Bahoi secara bertahap terus melengkapi sarana dan prasarana ekowisatanya, seperti adanya homestay yang sesuai standard, gazebo, jembatan penyeberangan wisatwan dilokasi objek wisata mangrove dan membentuk kelompok ekowisata yang membawahi kelompok kecil lain, seperti pemandu wisata, kerajinan, dan homestay.

Wilayah provinsi Sulawesi Utara saat ini sedang dalam masa pembangunan dan Kabupaten Kota juga terus melakukan pengembangan tersebut yaitu salah satu di Kabupaten Minahasa Utara. Di Minahasa Utara terdapat kawasan ekowisata tepatnya di Desa Bahoi Kecamatan Likupang Barat. Desa Bahoi Memiliki potensi sebagai Desa ekowisata sehingga sampai saat ini banyak wisatawan yang datang berkujung tetapi jumlah kunjungan tersebut belum terdata dengan baik. Kawasan Ekowisata Desa Bahoi Kecamatan Likupang Barat Kabupaten Minahasa Utara sudah ada sejak tahun 2010 tetapi tidak menunjukan perkembangan, sehingga muncul permasalah bagaimana atau apa saja faktor - faktor yang mempengaruhi wisatawan untuk datang berkunjung kekawasan ekowisata di Desa Bahoi, sehingga memerlukan penelitian dalam upaya untuk mempertahankan bahkan meningkatkan jumlah kunjungan wisatawan ke kawasan ekowisata di Desa Bahoi.

\section{Perumusan Masalah}

Berdasarkan latar belakang diatas, maka yang menjadi permasalahannya yaitu faktor apa saja yang mempengaruhi kunjungan wisatawan ke kawasan ekowisata Desa Bahoi, Kecamatan Likupang Barat, Kabupaten Minahasa Utara.

\section{Tujuan Penelitian}

Berdasarkan perumusan masalah yang diuraikan diatas, maka yang menjadi tujuan penelitian yaitu untuk mengetahui faktor faktor yang mempengaruhi kunjungan wisatawan ke kawasan ekowisata di Desa Bahoi. 


\section{Manfaat Penelitian}

Adapun manfaat dari penelitian ini diharapkan bisa memberikan informasi bagi pihak - pihak terkait tentang pengelolaan Kawasan Ekowisa Terhadap Pembangunan Wilayah Pesisir di Desa Bahoi, Kecamatan Likupang Barat, Kabupaten Minahasa Utara.

\section{METODOLOGI PENELITIAN}

\section{Lokasi dan Waktu Penelitian}

Lokasi penelitian ini dilakukan di Desa Bahoi, Kecamatan Likupang Barat, Kabupaten Minahasa Utara. dan waktu penlitian dilakukan selama 3 bulan dari bulan Mei 2016 sampai Juli 2016, mulai dari persiapan sampai selesai.

\section{Jenis dan Sumber Data}

Penelitian ini menggunakan data primer dan data sekunder. Data primer dikumpulkan melalui wawancara langsung dengan wisatawan dan sebagian masyarakan yang ada disekitar lokasi ekowsiata. Data sekunder diperoleh dengan cara mengumpulkan data dari instansi pemerintah Desa Bahoi, dan pemerintah Kabupaten Minahasa Utara dalam hal ini BAPEDA.

\section{Metode Pengumpulan Data}

Dalam penelitian ini, penulis menggunakan teknik sampling accidental yang dimana sampling accidental adalah, teknik penentuan sampel berdasarkan kebetulan, yaitu siapa saja yang secara kebetulan bertemu dengan peneliti dapat digunakan sebagai sampel. Responden diambil sebanyak 30 orang wisatawan.

\section{Konsep Pengukuran Variabel}

Variabel Yang diukur dalam penelitian ini adalah:

1. Aktivitas Kunjungan Wisatawan

Aktivitas kunjungan wisatawan ialah jenis kegiatan yang dilakukan wisatwan di tempat wisata dalam hal ini ke kawasan ekowisata mangrove dan diving.

2. Jarak yang ditempuh

Jarak yang ditempuh ialah jarak dari rumah sampai ke kawasan ekowisata Desa Bahoi dalam (KM)

\section{Tingkat Usia}

Tingkat usia ialah jenis usia yang datang berkunjung ke kawasan ekowisata Desa. Bahoi yang dihitung dalam bentuk Umur

4. Biaya Perjalanan

Biaya Perjalanan yaitu jumlah uang yang dikeluarkan selama perjalanan ke Kawasan Ekowisata Desa Bahoi, dalam satuan rupiah (Rp).

5. Biaya Masuk

Biaya Masuk yaitu biaya yang dikeluarkan pengunjung untuk masuk ke Kawasan Ekowisata Desa Bahoi sebagai partisipasi dalam pengelolaan kawasan ekowisata, yang dihitung dengan satuan rupiah (Rp).

\section{Metode Analisis Data}

Metode analisis data yang digunakan pada penelitian ini yaitu dengan menggunakan analisis regresi dengan model logit.

Dengan mempertimbangkan variable tak bebas dalam penelitian ini yang dihadapkan pada dua pilihan (Binary Choise), maka terdapat beberapa teknik analisa untuk memecahkan masalah - masalah seperti ini, seprti analisis diskriminan, analisis peluang linier dan analisa peluang logistik. Dalam penelitian ini, analisis diskriminan tidak dapat digunakan, karena tidak dapat mengestimasi peluang kejadian. Analisis peluang linier juga tidak dapat dipilih, Karen mengalami kelemahan formal, yaitu tidak mengandung kendala bagi nilai estimasi untuk berada dalam kisaran 0 sampai 1 yang menyebabkan residualnya bisa lebih kecil 0 maupun lebih besar 1. Model logistic adalah model yang cocok untuk dipakai dalam penelitian ini, mengingat variable tak bebasnya bersifat Binary Choise dalam ( 0 dan 1).

Model Regresi Logistik, sebagaimana fungsi regresi lainnya, digunakan juga untuk mrnggambarkan hubungan antara variable tak bebas dengan satu atau lebih variable bebas ( Neter, Wassermen, Kunter, 1989 dalam Rengkung 1997). Dengan demikian, dapat dikatakan bahwa model ini akan dapat berprediksi probabilitas suatu kejadian atau situasi dengan syarat atau kondisi adanya variable - variable tertentu. Probabilitas ini merupakan suatu conditional Probability (Sritua, 1993 dalam Rengkung 1997). 
Model Logit didasarkan pada fungsi peluang logistic kumulatif yang dispesifikasikan, sebagi berikut:

$$
\begin{array}{r}
P_{i}=F\left(\beta_{0}+\beta_{1} X_{1 i}\right)=\frac{1}{1+e^{-e_{i}}} \\
=\frac{1}{1+\mathrm{e}^{-\left(\beta_{0}+\beta_{1} X_{1 i}\right)}}
\end{array}
$$

Dalam fungsi diatas, $F$ merupakan frekuensi, e merupakan bilangan dasar logaritma natural (In) yang diperkirakan sama dengan 2.7182128 atau dibulatkan menjadi 2.71828. $\mathrm{P}_{\mathrm{i}}$ merupakan peluang bahwa suatu objek pengamatan akan tergolong kedalam kategori tertentu berdasarkan nilai tertentu dari variable bebas $\mathrm{X}_{1}$.

Persamaan diatas dapat juga dinyatakan dalam bentuk linier logaritmik, sebagai berikut:

$$
\begin{aligned}
& Z_{\mathrm{i}}=\operatorname{In}\left(\frac{\mathrm{P}_{\mathrm{i}}}{1-\mathrm{P}_{\mathrm{i}}}\right) \text { atau, } \quad \operatorname{In}\left(\frac{\mathrm{P}_{\mathrm{i}}}{1-\mathrm{P}_{\mathrm{i}}}\right)=\mathrm{Z}_{\mathrm{i}}= \\
& \beta_{0}+\beta_{1} \mathrm{X}_{1 \mathrm{i}}+\beta_{2} \mathrm{X}_{2 \mathrm{i}}+\beta_{3} \mathrm{X}_{3 \mathrm{i}}+\beta_{4} \mathrm{X}_{4 \mathrm{i}}
\end{aligned}
$$

Keterangan:

In $=$ Probabilitas

$Z_{i}=\beta_{0}+\beta_{1} X_{1 i}+\beta_{2} X_{2 i}+\beta_{3} X_{3 i}+\beta_{4} X_{4 i}$

$\mathrm{P}_{\mathrm{i}}=$ Aktivitas Kunjungan Wisatawan

$\mathrm{P}_{1}=$ Mangrove

$\mathrm{P}_{2}=$ Diving (Menyelam)

$\mathrm{B}_{0}=$ Intersep

$\mathrm{X}_{1}=$ Jarak Yang di Tempuh

$\mathrm{X}_{2}=$ Tingkat Usia

$\mathrm{X}_{3}=$ Biaya Perjalan

$\mathrm{X}_{4}=$ Biaya Masuk

\section{HASIL DAN PEMBAHASAN}

\section{Deskripsi Wilayah Penelitian}

Data mengenai keadaan umum wilayah Desa Bahoi Kecamatan Likupang Barat Kabupaten Minahasa Utara merupakan data - data sekunder yang bersumber dari data monografi desa yang diperoleh dari pemerintah setempat

\section{Letak Geografis}

Desa Bahoi secara administratif berada di Kecamatan Likupang Barat Kabupaten Minahasa Utara. Desa Bahoi terdiri dari 4 jaga lingkungan yaitu jaga I sampai dengan jaga IV.
Secara administratife, batas wilayahnya sebagai berikut:

$$
\begin{array}{ll}
\text { Sebelah Utata } & \text { : Desa Serei } \\
\text { Sebelah Selatan } & \text { : Desa Bulutui } \\
\text { Sebelah Timur } & \text { : Laut Likupang } \\
\text { Sebelah Barat } & \text { :Jalan Raya Serei }
\end{array}
$$

\section{Keadaan Penduduk}

Sebagaimana dengan daerah - daerah pesisir lainnya di Sulawesi Utara, keberdaaan masyarakat di daerah pesisir pantai mempunyai latar belakang yang beragam. Jumlah Penduduk Desa Bahoi 558 jiwa dan terdiri dari 160 Kepala Keluarga, dengan menempati wilayah pemukiman seluas \pm 150 Ha.

\section{Deskripsi Kawasan Ekowisata Desa Bahoi}

Bahoi adalah sebuah desa kecil di wilayah pesisir Sulawesi Utara yang memiliki Daerah Perlindungan Mangrove (DPM) dan Daerah Perlindungan Laut (DPL). Kawasan mangrove dan laut yang dilindungi ini sangat berarti bagi masyarakat Desa Bahoi yang sebagian besar penduduknya adalah nelayan. Masyarakat Desa Bahoi percaya kawasan yang dilindungi ini merupakan daerah untuk pemijahan berbagai jenis ikan.

Secara administrasi, Desa Bahoi terletak di Kecamatan Likupang Barat, Kabupaten Minahasa Utara, Provinsi Sulawesi Utara. Dengan jarak tempuh dari Ibukota Provinsi Sulawesi Utara yaitu Manado ke Desa Bahoi sekitar kurang lebih 1,5 jam dengan keadaan jalan normal dan dapat ditempuh dengan jalan darat baik menggunakan kendaraan roda dua ataupun kendaraan roda empat.

Bahoi mempunyai sejarah yang panjang sehingga masyarakat peduli untuk melestarian alam dan lingkungannya. Memang dahulu ditahun 1960 - an mangrove diwilayah Likupang cukup lebat sekali, namun masyarakat telah membabat sebagian tumbuhan mangrove tanpa memperhitungkan dampak. Namun, Sejak tahun 2002, pemerintah dan sebagian masyarakat Desa Bahoi berusaha untuk menyelamatkan wilayah lautnya, dan dari 18 Desa di Kecamatan Likupang Barat, ada beberapa Desa yang berhasil mempertahankannya dan salah satunya adalah Desa Bahoi, melalui Daerah Perlindungan Laut. 


\section{Aktivitsa Kunjungan yang dilakukan Wisatawan}

Aktivitas kunjungan yang dilakukan wisatawan di Desa Bahoi sesuai hasil penelitian adalah menikmati keindahan mangrove dan diving, Kegiatan tersebut baik itu yang dilakukan oleh wisatawan lokal maupun wisatawan mancanegara. Hasil penelitian menunjukan bahwa terdapat 19 wisatawan yang melakukan aktivitas kunjungan di Bahoi untuk diving. Dimana hasil ini diperoleh dari wawancara langsung terhadap responden yang dijadikan sampel untuk pengambilan data. Hasil perhitungan aktivitas kunjungan wisatawan dapat dilihat pada Tabel 1 berikut.

Tabel 1. Hasil Analisis Aktivitas Kunjungan Wisatawan di Desa Bahoi

\begin{tabular}{cccc}
\hline No & $\begin{array}{c}\text { Aktivitas Kunjungan } \\
\text { Wisatawan }\end{array}$ & $\begin{array}{c}\text { Jumlah } \\
\text { Responden }\end{array}$ & $\begin{array}{c}\text { Persentasi } \\
(\boldsymbol{\%})\end{array}$ \\
\hline 1 & Mangrove & 11 & 36,6 \\
2 & Diving & 19 & 63.4 \\
\hline & Total & 30 & 100 \\
\hline
\end{tabular}

\section{Jarak Yang Ditempuh Wisatawan Sampai di Desa Bahoi}

Pada variabel ini, khususnya variabel jarak yang ditempuh wisatawan dari tempat tinggal sampai di Desa Bahoi. Dimana Wisatawan yang sering berkunjung berasal dari luar wilayah Likupang Barat atau dapat kita katakan sangat jauh. Sebanyak 10 responden berasal dari luar wilayah likupang atau dapat dikatakan sangat jauh yaitu dengan nilai persentase sebanyak 33,3\%. Adapun hasil penelitian ini diperoleh dari hasil wawancara langsung dengan responden yang dijadikan sampel untuk pengambilan data.

Tabel 2. Hasil Perhitungan Jarak yang Ditempuh

\begin{tabular}{cccc}
\multicolumn{4}{c}{ Wisatawan ke Desa Bahoi } \\
\hline No & $\begin{array}{c}\text { Jarak Yang } \\
\text { Ditempuh (Km) }\end{array}$ & $\begin{array}{c}\text { Jumlah } \\
\text { Responden }\end{array}$ & $\begin{array}{c}\text { Persentase } \\
(\boldsymbol{\%})\end{array}$ \\
\hline 1 & Dekat $(70-99)$ & 6 & 20 \\
2 & Jauh $(100-149)$ & 14 & 46.7 \\
3 & Sangat Jauh $(150-190)$ & 10 & 33.3 \\
\hline & Total & 30 & 100 \\
\hline
\end{tabular}

\section{Biaya Perjalanan Wisatawan Kedasa Bahoi}

Dalam perjalanan ke Desa Bahoi, wisatawan menggunakan biaya perjalanan seperti menyewa kendaraan, biaya konsumsi, dan lain sebaginya. Biaya perjalanan wisatawan yaitu sebanyak 11 responden mengeluarkan biaya $\mathrm{Rp}$. 200.000 - 399.999, dan sebanyak 19 responden mengeluarkan biaya Rp.400.000 - 650.000.
Tabel 3. Hasil Perhitungan Biaya Perjalanan Wisatawan ke Desa Bahoi

\begin{tabular}{cccc}
\hline No & Biaya Perjalanan (Rp) & $\begin{array}{c}\text { Jumlah } \\
\text { Responden }\end{array}$ & Persentase \% \\
\hline 1 & $200.000-399.999$ & 11 & 36.7 \\
2 & $400.000-650.000$ & 19 & 64.3 \\
\hline & Jumlah & 30 & 100 \\
\hline
\end{tabular}

\section{Biaya Masuk Wisatawan Kekawasan Wisata di Desa Bahoi}

Dalam kawasan ekowisata sering kita temui kewajiban wisatawan salah satunya adala mebayar biaya masuk, khusus dikawasan wisata Desa Bahoi, Biaya Masuk saat ini masih kurang jelas, kadang Rp. $5000-10.000$ dari hasil pengambilan data, yang didapatkan dari 30 responden jumlah keseluruhan biaya masuk dalam satu kali kunjungan sebesar Rp. 246.000,-.

Tabel 4. Hasil Perhitungan Biaya Masuk Wisatawan ke Desa Bahoi

\begin{tabular}{cccc}
\hline No & Biaya Masuk (Rp) & $\begin{array}{c}\text { Jumlah } \\
\text { Responden }\end{array}$ & $\begin{array}{c}\text { Jumlah } \\
(\mathbf{R p})\end{array}$ \\
\hline 1 & 5 & 9 & 45 \\
2 & 7 & 3 & 21 \\
3 & 10 & 18 & 180 \\
\hline & Jumlah & 30 & 246.000 \\
\hline
\end{tabular}

\section{Tingkat Usia Wistawan yang Berkunjung ke Desa Bahoi}

Berdasarkan hasil pengambilan sampel yang dilakukan ditempat wisata Desa Bahoi, tingkat usia wisatawan yang berkunjung dari usia 19 - 27 sebanyak 16 orang, usia 28 - 35 sebanyak 7 orang dan usia $36-43$ sebanyak 7 orang.

Tabel 5. Tingkat Usia Wisatawan yang Berkunjung ke Desa Bahoi

\begin{tabular}{clcr}
\hline No & $\begin{array}{l}\text { Kelompok Umur } \\
\text { (Tahun) }\end{array}$ & $\begin{array}{c}\text { Jumlah } \\
\text { Responden }\end{array}$ & Persentase \% \\
\hline 1 & $19-27$ & 16 & 53.4 \\
2 & $28-35$ & 7 & 23.3 \\
3 & $36-43$ & 7 & 23.3 \\
\hline & Jumlah & 30 & 100 \\
\hline
\end{tabular}

Hasil Analisis Faktor Faktor Yang Mempengaruhi Kunjungan Wisatawan ke Kawasan Ekowisata di Desa Bahoi

Berdasarkan analisis yang telah dilakukan untuk mengetahui faktor yang mempengaruhi kunjungan wisatawan ke kawasan ekowisata di Desa Bahoi, yaitu Aktivitas Kunjungan yang Dilakukan Wisatawan (Y), Jarak yang ditempuh (X1), Tingkat Usia (X2), Biaya Perjalanan (X3) dan Biaya Masuk (X4). 
Dari hasil analisi faktor - faktor yang mempengaruhi kunjungan wisatawan Kawasan Ekowisata di Desa Bahoi, maka diperoleh hasil estimasi sebagai berikut:

$Y^{\prime}=-5,13+0,0056 \mathrm{X} 1+0,1160 \mathrm{X} 2+0,000001 \mathrm{X} 3-0,000009 \mathrm{X} 4$

Secara keseluruhan bahwa variabel independen yaitu jarak (X1), Tingkat Usia (X2), Biaya Perjalanan (X3), Biaya Masuk (X4) mempengaruhi keputusan wisatawan untuk mengunjungi wisata mangrove dan wisata diving.

Tabel 6. Hasil Analisis Binary Logistik

\begin{tabular}{cccccc}
\hline Source & DF & Adj Dev & $\begin{array}{c}\text { Adj } \\
\text { Mean }\end{array}$ & $\begin{array}{c}\text { Chi- } \\
\text { Square }\end{array}$ & $\begin{array}{c}\text { P- } \\
\text { Value }\end{array}$ \\
\hline Regression & 4 & 45,225 & 113,061 & 4,52 & 0,340 \\
X1 & 1 & 0,0974 & 0,09739 & 0,10 & 0,755 \\
X2 & 1 & 34,953 & 349,527 & 3,50 & 0,062 \\
X3 & 1 & 0,1029 & 0,10289 & 0,10 & 0,748 \\
X4 & 1 & 0,0023 & 0,00233 & 0,00 & 0,961 \\
\hline Error & 25 & 349,070 & 139,628 & & \\
\hline Total & 29 & 394,295 & & & \\
\hline
\end{tabular}

R-Sq=11,47\% R-Sq(Adj)=1,33\% AIC=44,91

Output diatas untuk menjelaskan tentang signifikansi pengeruh variabel bebas terhadap variabel tidak bebas secara parsial. Dalam penelitian ini, terdapat empat variabel bebas, yaitu jarak yang ditempuh, tingkat usia, biaya perjalanan, dan biaya masuk sedangkan variabel tidak bebas adalah ekowisata mangrove atau ekowisata diving.

Hasil menunjukan bahwa terdapat satu variabel yaitu Tingkat Usia $(\mathrm{P}<0.062)$, artinya variabel tersebut mempunyai pengaruh yang signifikan terhadap peluang berkunjung kewisata diving. Sedangkan variabel Jarak yang ditempuh, Biaya perjalanan dan Biaya masuk memiliki nilai $\mathrm{P}>0,90$, artinya variabel tersebut tidak memiliki pengaruh yang signifikan terhadap kunjungan wisatawan ke wisata Diving.

Berdasarkan hasil penelitian, maka dihasilkan satu variabel bebas yang memiliki pengaruh yang signifikan yaitu Tingkat Usia, sehingga model logistik yang dibangaun dalam penelitian ini adalah sebagai berikut:

$\mathrm{Pi}=\mathrm{F}\left(\beta_{0}+\beta_{1} \mathrm{X}_{1 \mathrm{i}}\right)=\frac{1}{1+\mathrm{e}^{-\mathrm{Z}_{\mathrm{i}}}}$

$\mathrm{Z}_{\mathrm{i}}=3,24-0,062$ Tingkat Usia

$\mathrm{P}_{\mathrm{i}}=\frac{1}{1+\mathrm{e}^{-(3,24-0,062 \mathrm{X} 2)}}$
Berdasarkan persamaan diatas, maka dapat dihitung probabilitas atau prediksi peluang wisatawan memilih tempat wisata kewisata mangrove atau wisata diving.

Hasil analisis regresi menunjukan bahwa koefisien dugaan pada variabel $\mathrm{X} 2$ atau Tingkat usia adalah 0,1160 dan variabel tersebut bernilai positif artinya bahwa variabel X2 atau tingkat usia berpengaruh pada kunjungan wisatawan ke ekowisata diving.

\section{Faktor - faktor Pendorong Wisatawan} Mengunjungi Tempat Wisata di Desa Bahoi

Dari hasil penelitian terdapat beberapa faktor - faktor pendorong wisatawan mengunjungi suatu tempat wisata khususnya Desa Bahoi, yaitu objek wisata, sarana jalan, transportasi, serta saran akomodasi dan makanan.

\section{Objek Wisata}

Sebagimana yang kita ketahui objek wisata adalah segala sesuatu yang ada di daerah tujuan wisata yang merupakan daya tarik, agar orang - orang mau datang berkunjung ke tempat tersebut. Kabpaten Minahasa Utara memiliki beberapa tempat wisata khususnya diwilayah Likupang Barat yang terdapat begitu banyak tempat wisata nan indah dan salah satunya ada di Desa Bahoi, Kecamatan Likupang Bartat.

\section{Saran Jalan di Desa Bahoi}

Desa Bahoi memiliki panjang jalan kurang lebih $3 \mathrm{Km}$. berdasarkan profil desa, Desa Bahoi memiliki tiga jenis jalan yaitu jalan baik dengan panjang $2 \mathrm{Km}$, jalan sedang dengan panjang $600 \mathrm{~m}$, dan jalan rusak dengan panjang $400 \mathrm{~m}$. Dari hasil survey terakhir akses jalan yang terdapat di Desa Bahoi sangat memperihatinkan khususnya jalan menuju kawasan ekowisata yang bisa dibilang rusak berat, karena terdapat lubang dan batu - batu besar ditengah jalan sehingga membuat perjalan menuju kawasan ekowisata terganggu dan akibatnya tingkat kunjungan wisatawan untuk datang di Desa Bahoi berkurang. 


\section{Sarana Transportasi}

Dari hasil survey lokasi, sarana transportasi ke Desa Bahoi adalah baik, karena memiliki alat transportasi yang lengkap baik kendaraan roda dua maupun kendaraan roda empat, dan juga kondisi jalan yang baik dari kota likupang menuju Desa Bahoi.

\section{Sarana akomodasi dan Makanan}

Sarana akomodasi di Desa Bahoi sudah dapat dikatakan baik bahkan juga kurang baik, karena wisatawan yang datang ke Desa Bahoi sudah disediakan sarana akomodasi yaitu tempat penginapan atau homestay bagi wisatawan yang ingin bermalam di Desa Bahoi tetapi masih kurang, dan rumah makan yang menyediakan masakan kuliner khas Desa Wisata, dan kurangnya tempat belanja oleh oleh atau cendramata khas Desa Wisata.

\section{KESIMPULAN DAN SARAN}

\section{Kesimpulan}

Berdasarkan hasil penelitian menunjukan bahwa aktivitas kunjungan yang menjadi tujuan wisatawan untuk berkunjung ke kawasan ekowisata Desa Bahoi adalah wisata diving dan faktor yang mempengaruhi dalam penelitin ini adalah variabel tingkat usia.

Hasil analisis regresi menunjukan bahwa koefisien dugaan pada variabel Tingkat usia adalah 0,1160 dan variabel tersebut bernilai positif artinya bahwa variabel tingkat usia berpengaruh pada kunjungan wisatawan ke ekowisata diving.

\footnotetext{
Saran

Perlu adanya penelitian yang lebih lanjut untuk mengetahui kembali pengembangan ekowisata yang ada di Desa Bahoi sehingga mendapatkan gambaran wisata alam yang lebih nyata. Serta keterlibatan pemerintah pihak terkait, yakni masyarakat sebagai pengelola dan pemerintah Desa Bahoi lebih memperhatikan kelestarian lingkungan di ekowisata. Dan juga peran pemerintah Kabupaten Minahasa Utara, dalam hal ini Dinas Pariwisata agar lebih ditingkatkan lagi dalam hal pengembangan Ekowista, khususnya di Ekowisata Desa Bahoi, berupa pengadaan sarana dan prasarana yang lebih memadai.
}

\section{DAFTAR PUSTAKA}

,2003. Dahuri, R. 2003.

Keanekaragaman Hayati Laut :

Aset Pembangunan Berkelanjutan

Indonesia. Gramedia Pustaka

Utama. Jakarta.

Dahuri, 2001. Pengelolaan Sumberdaya

Wilayah Pesisir dan Laut

Secara Terpadu edisi ke-3. PT.

Paradnya Paramita. Jakarta.

Fandeli, Chafid dan Mukhson. 2000.

Pengusahaan Pariwisata.

Pustaka Pelajar Offset. Yogyakarta.

Goeldner, C.R. and J. R. Brent Ritchie, 2003. Tourism principles: Practices, philosophies. New Jersey: John Wiley inc. America.

Hosmer, D. W. 2011. Applied Logistic Regression, 2nd ed. Chichester Wiley. New York.

Iskandar, A. Rizal, E. dan Rosfiantika, E. 2012. Pengelolaan Informasi di Pusat Data Redaksi dan Pengembangan Program Harian Umum Pikiran rakyat Bandung: Jurnal Universitas Komunikas. 1, (1): 01-16.

Kawasan Ekowisata. Jakarta.

Lascurain, C. H. 1996. Tourism, Ecotourism And Protected Area. IUCN. Switzerland

Nugroho, I. 2009. Pengembangan Ekowisata Dalam Pembangunan Daerah. Skripsi Institut Pertanian Bogor. Bogor.

Pitana, I. gede dan Gayatri G. 2005. Sosiologi Pariwisata. Andi. Undang - undang Republik Indonesia No. 10 Tahun 2009 tentang Kepariwisataan. Yogyakarta.

Safitri, A. R. 2012. Analisis Peluang Pokok Terhadap Pendapatan Sewa Angkutan Batu Bara Dalam Kaitannya Dengan Perencanaan Laba PT. XYZ Makasar. Universitas Hasanuddin. Makasar. 
Sastrayuda, G. S., 2010. Konsep Pengembangan Kawasan Ekowisata. Jakarta

Satria, D. 2009. Strategi Pengembangan Ekowisata Berbasis Ekonomi Lokal Dalam Rangka Program Pengentasan Kemiskinan Di Wilayah Kabupaten Malang. Malang: Journal Of Indonesia Applied Economics. 3.(1): 37-47.

Stanis, S. 2005. Pengelolaan Sumberdaya Pesisir Dan Laut Melalui Pemberdayaan KearifanLokal di Kabupaten Lembata Provinsi Nusa Tenggara Timur. Tesis Program Pascasarjana Universitas Diponegoro, Semarang.
Supriharyono. 2009. Konservasi Ekosistem Sumberdaya Hayati Di Wilayah Pesisir dan Laut Tropis. Pustaka Belajar. Yogyakarta

Tuwo, H. A., 2011. Pengelolaan Kawasan Ekowisata Pesisir dan Laut. Brilian Internasional. Surabaya.

Wibowo. 2007. Dampak Pengembangan Ekowisata Kawasan Wisata Gunung Merapi Merbabu Terhadap Perubahan Struktur masyarakat. Universitas Sebelas Maret. Sukarta.

Widjanarko, M dan Wismar, D. 2011. Identifikasi

Sosial Potensi Ekowisata Berbasis Peran Masyarakat Lokal. Semarang: Jurnal Fakultas Psikolog UNDIP. 9, (1): 01-07. 